*Doutorando em Direito Político e Econômico pela Universidade Presbiteriana Mackenzie. Mestre em Direito pela Universidade Nove de Julho - UNINOVE. Especialista em Direito Constitucional e Administrativo pela Universidade Estácio de Sá. Especialista em Direito Tributário pelo Centro Universitário das Faculdades Metropolitanas Unidas - FMU. E-mail: jeferson@joliveiraadv.com. br

**Doutor e mestre em Direito pela Pontifícia Universidade Católica de São Paulo (PUC/SP). Professor permanente do Mestrado em Direito e da Graduação da Universidade Nove de Julho (UNINOVE). Professor Convidado da Pós Graduação lato sensu da PUC/COGEAE e da Escola Paulista da Magistratura. E-mail: benamarcelo@gmail.com

\section{Princípios Constitucionais da Ordem \\ Econômica como Diretrizes do Desenvolvimento SOCIOECONÔMICO BRASILEIRO}

\author{
Constitutional Principles of the Economic Order \\ as Guidelines for BrazILIAN SOCIO-ECONOMIC \\ DEVELOPMENT
}

\section{Jeferson Sousa Oliveira* Marcelo Benacchio**}

Como citar: OLIVEIRA, Jeferson Sousa; BENACCHIO, Marcelo. Princípios constitucionais da ordem econômica como diretrizes do desenvolvimento socioeconômico brasileiro. Revista do Direito Público, Londrina, v. 15, n. 1, p. 100-113, abr. 2020. DOI: 10.5433/24157-108104-1.2020v15n1p. 100. ISSN: $1980-511 \mathrm{X}$

Resumo: Com a célere integração econômico-financeira propiciada pela globalização, as atividades desenvolvidas pelas empresas acabaram sendo transnacionalizadas, instigando diversos Estados não desenvolvidos a buscarem meios de atrailas para seus territórios, almejando promover o desenvolvimento nacional. Entretanto, isso possibilitou a ocorrência de inúmeros abusos ao poder econômico, ensejando o ganho de poder político por parte das organizações empresariais, refletindo, inclusive, em uma gama de violações aos direitos sociais em diferentes Estados. Destarte, busca-se analisar os princípios constitucionais econômicos, notadamente sob uma vertente de delimitação das relações de mercado e um viés protetivo à dignidade humana, de maneira a contribuir com as discussões sobre o tema. Para tanto, utiliza-se o método hipotético-dedutivo, valendo-se de estudos bibliográficos. Conclui-se que o mercado interno possui significativa importância para o desenvolvimento do país, devendo contar com certo grau de dirigismo político a fim de impedir que o exercício da atividade econômica viole garantias públicas.

Palavras-chave: Globalização. Mercado. Desenvolvimento. Empresas transnacionais. Direito econômico.

Abstract: With the fast economic-financial integration brought about by globalization, activities developed by the companies were eventually transnationalized, instigating several developing states to seek ways of attracting them to their territories, as a way to promote national development. However, this has led 
to numerous abuses of economic power, resulting in the gaining of political power by business organizations, reflecting a range of violations of social rights in different states. The purpose of this study is to analyze the constitutional economic principles, notably under a delimitation of market relations and a protective bias towards human dignity, in order to contribute to the discussions on this subject. Moreover, this paper used the hypotheticaldeductive model and literature review. Furthermore, this research concludes that the internal market has significant importance for the development of emerging economies, and should have some measure of political leadership in order to prevent the violation of public rights and guarantees.

Keywords: Globalization; Marketplace; Development; Transnational Corporations; Economic Law. 


\section{CONSIDERAÇÕES INICIAIS}

O processo de globalização tem moldado constantemente a forma com a qual o relacionamento comercial ocorre no mundo moderno. Fruto da evolução dos meios de comunicação, as relações comerciais adotaram um modelo de integração que foi capaz de vincular Estados e empresas na busca pela realização de seus anseios financeiros.

Assim, cada vez mais as empresas desejam ser capazes de utilizar os benefícios trazidos pela globalização, tornando-se transnacionais, mobilizando sua atividade e reduzindo seu custo operacional.

No entanto, a fim de atrair a presença dessas organizações, muitos Estados acabam por ceder à influência por elas exercida, sobrepondo seus interesses e mitigando direitos sob a crença de beneficiar toda a coletividade e aquecer o mercado interno.

Com isso, por vezes, garantias são mitigadas em proveito do capitalismo predatório, tornando o individuo mero insumo na cadeia produtiva, ainda que o lucro, embora importante, não deva ser buscado como um fim em si, mas como um instrumento para o desenvolvimento humano.

Nesse contexto, a Constituição Federal previu diversos princípios regentes da ordem econômica nacional, os quais visam ordenar o mercado interno de modo a promover o desenvolvimento pátrio, sem que disso resulte o sacrifício da dignidade do povo brasileiro, entendida como um dos fundamentos da República.

Deste modo, o presente trabalho possui caráter analítico, o qual se valerá do método hipotético-dedutivo e de estudos bibliográficos a fim de abordar a problemática proposta. Buscase ainda, levantar questionamentos a respeito dos reflexos negativos da globalização atinentes à dignidade da pessoa humana, a partir da atuação das empresas transnacionais e sua relação com os Estados. Em outras palavras, questiona-se, dentro da relação Estado-Empresa-Sociedade, a possibilidade de conciliar o desenvolvimento econômico nacional a partir mercado globalizado, sem que disso resultem violações ao bem-estar do povo brasileiro.

Para tanto, adota-se como referencial teórico a doutrina de Joseph E. Stiglitz e John Gerand Ruggie, no que toca à globalização e seus reflexos socioeconômicos, bem como do posicionamento adotado por Eros Roberto Grau, relativamente à ordem econômica nacional e o desenvolvimento do país através do mercado.

\section{GLOBALIZAÇÃO E EMPRESAS TRANSNACIONAIS}

Atualmente, ante o ápice do desenvolvimento tecnológico e do aprimoramento dos meios de transporte e comunicação, informações que outrora levariam dias ou semanas para circularem pelo mundo passaram a se propagar em velocidade nunca antes testemunhada.

A expansão das relações comerciais entre diferentes povos, impulsionada pela vontade de descobrir o novo e ampliar os ganhos, fez com que a humanidade caminhasse em direção ao que hoje se entende por globalização. 
Este processo de evolutiva integração entre povos possibilitou o estabelecimento de novos tipos de interação social, econômica e financeira, de modo a influir diretamente no exercício da atividade comercial e nas políticas de mercado adotadas em diversos países.

O movimento de globalização ressurgiu com uma promessa antiga do capitalismo, o desenvolvimento a todos os povos, tornando latente a crença na ascensão dos padrões de vida por todo o mundo moderno, entretanto, na realidade, o que ocorreu foi o aumento da pobreza nas duas últimas décadas (STIGLITZ, 2007), beneficiando apenas determinados grupos, especialmente aqueles detentores de vasto poder econômico, como as empresas.

O processo de desenvolvimento da globalização foi intensificado a partir da difusão do sistema capitalista pelo mundo, pois a mobilidade das companhias e a rápida realização de negócios, mais do que uma realidade, se tornou uma necessidade.

Assim, o capitalismo demonstrou ser o sistema mais adequado para atender os anseios humanos, sobrepondo-se ao decorrer dos anos ao sistema socialista, que, embora possua uma base ideológica de proteção social, não foi executado com toda sua pureza nos países que o adotaram, salvo a China e Cuba, os quais têm flexibilizado suas políticas econômicas a fim de receberem investimentos externos (TAVARES, 2011).

Com a ascensão dos agentes econômicos a nível internacional e o aumento dos casos de exploração desregrada do trabalho em muitos países, clamou-se pela presença estatal no cenário comercial, a fim de estabelecer limites à atuação daqueles que o integram, visando resguardar direitos tidos como necessários ao bem-estar de todos.

Diversas formas de intervencionismo foram criadas e aplicadas dentro do modelo capitalista, todos objetivando a busca pelo desenvolvimento econômico, e alguns deles, demonstrando certo grau de preocupação com os seres humanos, por exemplo, Estado do Bem-Estar Social ${ }^{1}$.

Embora as ideias trazidas por Adam Smith (2015) quanto ao liberalismo econômico visassem o desenvolvimento social a partir de um mercado autorregulado, isso não se mostrou totalmente eficaz, pois com o passar do tempo, discrepâncias econômicas se acentuaram na sociedade, definindo classes e ensejando constantes desrespeitos aos direitos individuais por parte daqueles que detinham a propriedade dos meios de produção. Em outras palavras, é possível afirmar que a sociedade passou a ser regida pelos desejos do mercado.

Com o advento do neoliberalismo, idealizado a partir da doutrina de John Maynard Keynes - na obra Teoria geral do emprego, dos juros e da moeda - como resposta à crise capitalista que ficou conhecida como a Grande Depressão (VASCONCELLLOS; GARCIA, 2008, p. 17), passouse a admitir a intervenção ${ }^{2}$ estatal na economia de forma mais ampla que os sistemas anteriores,

1 “[...] Os economistas clássicos e neoclássicos propõem uma separação mais sensível entre o Estado e o mercado. Teorias econômicas neoclássicas mais ortodoxas, como a de Adam Smith, em A riqueza das nações, sustentam que as funções básicas do Estado devem restringir-se à defesa, ao direito como regulador de alguns fatos sociais, como a propriedade privada, a estrutura da competição e da cooperação e, por fim, a ordem. As teorias estruturalistas, as quais defendem uma atuação mais extensiva do Estado na economia, defendem que as funções do Estado extrapolam a capacidade de determinação e garantia do sistema jurídico, devendo também criar condições materiais de produção, mais comumente conhecida como a infraestrutura, além de garantir a mediação entre salário e capital" (ARAGÃO, 2017, p. 30).

2 Ainda que se conheça a divergência doutrinária quanto ao emprego do termo "intervenção" para se falar em atuação do Estado na economia (ARAGÃO, 2017), opta-se por adotar o referido termo ante a sua usualidade, tanto para 
agindo o Estado como agente regulador, a fim de que fosse mantido o equilíbrio do mercado necessário para o exercício da atividade econômica. ${ }^{3}$

Destarte, o modelo neoliberal passou a ser o mais adotado pelos Estados desde então, moldando o posicionamento do ente público em relação ao mercado, obrigando-o a estabelecer limites ao exercício da atividade negocial no mercado interno. Anos mais tarde, com o desenvolvimento das relações de mercado e a expansão da integração social, ao perceberem o potencial lucrativo da internacionalização de suas atividades, diversas empresas logo buscaram se adaptar ao novo cenário a fim de reduzir seus custos e ascender seus ganhos.

$\mathrm{O}$ atual dinamismo da atividade comercial no mundo e seu célere fluxo monetário fez com que a mobilidade da atividade econômica se tornasse um instrumento essencial para aqueles que desejam explorar novos mercados, vez que "[...] a imobilidade não é uma opção realista num mundo em permanente mudança" (BAUMAN, 1999, p. 8).

Tal fator contribuiu para o surgimento das chamadas empresas transnacionais, ou seja, organizações corporativas que passaram a possuir sua estrutura difundida em mais de um país.

As empresas transnacionais - que se caracterizam por possuir a matriz em um país e atuação em diversos outros -, destacaram-se no cenário da globalização desempenhando papel determinante nas relações internacionais, que ultrapassam o âmbito econômico. Questões sociais, ambientais, de garantia de direitos dos trabalhadores e de sua dignidade estão nesta pauta (RIBEIRO; OLIVEIRA, 2016, p. 30).

Dentre os diversos questionamentos que rodeiam a atuação das empresas transnacionais atualmente, está a preocupação com os Direitos Humanos, pois os poderes pertencentes a tais organizações "[...] se expandiram além do alcance de sistemas eficientes de governança pública, criando ambientes permissivos para atos abusivos por parte das companhias, sem sanções ou reparações adequadas" (RUGGIE, 2014, p. 26).

Assim, encontra-se dificuldade em submetê-las a um efetivo sistema normativo internacional ${ }^{4}$, visando coibir que condutas comerciais socialmente lesivas fiquem impunes em decorrência de sua força política ${ }^{5}$.

versar sobre a atuação do Estado na economia quanto sobre a mesma.

3 Nesse sentindo, destaca-se que assegurar o correto equilíbrio do mercado não traz benefícios apenas para as relações negociais, mas também para a sociedade de modo geral, vez que impede que a coletividade se submeta a situações laborais que violem garantias legais previamente estabelecidas em decorrência de eventuais abusos do poder econômico.

4 "Empresas que operam globalmente, não são regulamentadas como tal. Em vez disso, cada uma das entidades que as compõem individualmente está sujeita à jurisdição nas quais ela atua. Mas, mesmo nos países em que as leis nacionais condenam a conduta abusiva, o que não pode ser sempre subestimando, os Estados muitas vezes deixam de implementá-las - devido à falta de capacidade, ao medo das consequências que podem ser geradas pela concorrência ou porque seus líderes colocam os ganhos particulares acima do bem-estar público.” (RUGGIE, 2014, p. 18).

5 A força política das transnacionais, por diversas vezes, ensejou danos sociais ao redor do planeta, podendo-se citar inúmeros casos. Por exemplo, "no Peru, uma mineradora chegou ao ponto de pressionar o governo a não examinar as crianças que viviam perto de suas minas para ver se haviam sido expostas a riscos de saúde. A certa altura, PapuaNova Guiné aprovou uma lei que tornava ilegal processar companhias mineradoras internacionais fora do país, mesmo para fazer valer direitos legais, ambientais ou de saúde, temendo que esses processos desestimulassem os investimentos no país" (STIGLITZ, 2007, p. 313). 


\section{REFLEXOS SOCIAIS DA ATUAÇÃO DAS TRANSNACIONAIS}

Em meio a Era da Informação, para que uma atividade comercial seja desenvolvida de maneira eficiente, faz-se imprescindível a existência de algum tipo de apoio advindo do Estado, principalmente no que tange a atuação das empresas nacionais, essenciais ao desenvolvimento do mercado interno.

Entretanto, benefícios são concedidos também a empresas estrangeiras. Diversos países reduzem as obrigações das transnacionais detentoras de notória influência no cenário internacional a fim de que estas se instalem em seu território, o que é feito, por vezes, através de subsídios e isenções fiscais.

O problema surge quando estas empresas migram para países periféricos não apenas em busca de mão de obra barata e incentivos fiscais, mas também de influência política, a qual é conquistada através de seu poder econômico ${ }^{6}$.

Possuir poder político enseja maior facilidade para a iniciativa privada em sobrepor seus interesses àqueles pertencentes ao Estado, o que pode comprometer a justiça social, restringindo a atuação do ente público quando do exercício do poder de polícia administrativa ${ }^{7}$, sujeitando a sociedade aos interesses do mercado. Nessa esteira, Daniela Menengoti Ribeiro e Jose Sebastiao de Oliveira (2016, p. 30), afirmam que "a grande inquietação quanto à atuação das empresas transnacionais é seu comprometimento com os direitos humanos em países onde há falhas legislativas para sua efetiva garantia."

O Estado, por seu turno, também é responsável pela mitigação e ausência de efetivação de direitos, pois cedendo aos interesses privados, o Poder Público opta por suprimir garantias ou adotar um posicionamento passivo na proteção de sua população, vulnerando seu povo à própria sorte.

A partir disso, é possível falar na precificação do meio ambiente e da vida humana, vez que "o dinheiro fala alto em todos os países, mas fala especialmente mais alto nos países em desenvolvimento." (STIGLITZ, 2007, p. 315). Corroborando com tal assertiva, José Renato Nalini (2015, p. 11) dispõe que "o dinheiro anestesia a consciência. Em nome dele, tudo se legitima."

Max Weber (2004, p. 46) traz que ante a inversão de valores causada pelo capitalismo, o ser humano vive “[...] em função do ganho como finalidade da vida, não mais o ganho em função

6 “"...] quando o empresário atua no mercado em busca de um determinado objetivo, se ele não consegue atingi-lo por via diplomática, ele vai tentar obtê-lo por vias, digamos, 'violentas', pelo lobby, pela captura de agências e assim por diante" (NUSDEO; MAGLIANO; FERRAZ JUNIOR, 2009, p. 6).

7 "A Microsoft tem tanto poder de mercado que ameaçou descaradamente se retirar da Coréia do Sul se o país continuasse com seu processo antitruste contra a empresa - em certo sentido, confirmando as alegações de poder de mercado arrogante, pois se isso não fosse verdade, sua ameaça de se retirar não faria sentido." (STIGLITZ, 2007, p. 134).

8 A relação entre Direitos Humanos e atividade econômica é de significativa importância para muitos, o que resultou em diversas tentativas de conciliar ambos os interesses, no entanto, os agentes econômicos privados opuseram-se ao que eles entenderam como uma privatização de direitos, cabendo ao Estado e não ao mercado assegurá-los. Nessa linha, podendo-se citar, por exemplo, os chamados Guiding Principles on Business and Human Rights, que, em linhas gerais, traz que "[...] os Estados devem proteger; as companhias devem respeitar; e aqueles que foram prejudicados devem ser indenizados" (RUGGIE, 2014, p. 23). 
do ser humano como meio destinado a satisfazer suas necessidades materiais." 9

Embora muito se acredite que a atividade econômica é exercida com o intuito exclusivo de gerar lucro, é errônea a adoção de tal posicionamento, pois como afirma Amartya Sen (2010, p. 28), "a riqueza evidentemente não é o bem que estamos buscando, sendo ela meramente útil e em proveito de alguma outra coisa". O que se busca, na verdade, é o desenvolvimento social e a melhoria da qualidade de vida de cada indivíduo.

Ademais, a transnacionalização da atividade econômica não é de todo mal, vez que tem cumprido seu papel em propiciar a expansão da competitividade entre as empresas, o que também é benéfico aos consumidores, à medida que possibilita a transferência de tecnologia, redução dos preços e o aperfeiçoamento da educação nacional.

Entretanto, não se pode olvidar que a atuação das transnacionais ocorre com base nas determinações de investidores ${ }^{10}$. Embora possa haver organizações empresariais preocupadas com a opinião de seus stakeholders (empregados, fornecedores, clientes etc.), estas declarações, por muito tempo, foram consideradas irrelevantes ao versarem sobre a maneira como aquelas deveriam ser dirigidas. No entanto, a sociedade tem causando a mudança desse entendimento à medida que a difusão das informações enseja maior transparência e notoriedade dos fatos, influenciando diretamente a imagem social da empresa, e, consequentemente, seu desempenho no mercado.

Desta maneira, almejando evitar a aquisição de uma imagem comercial negativa, algumas empresas participam anualmente de programas sociais, os quais são apresentados à coletividade como um instrumento de propaganda, o qual se denomina marketing social(CUNHA; DOMINGOS, 2011).

Dentre as diversas formas de marketing social adotadas no mundo, inclusive no Brasil, comumente as empresas se valem daquelas medidas que visam preservar o meio ambiente. Entretanto, transmitir uma imagem ambientalmente correta não justifica incorrer em violações a outros direitos.

Não basta à empresa se autodenominar ecologicamente correta, se incide e reincide em más práticas ambientais e mostra que sua opção ecológica é mero marketing. Verdade, franqueza, transparência, são valores que nem as pessoas, nem as entidades formadas para os mais distintos objetivos podem descuidar (NALINI, 2011, p. 121).

Tornou-se moralmente inaceitável a atuação de companhias que desrespeitem direitos trabalhistas, ambientais, consumeristas, entre outros. No entanto, ao mesmo tempo em que

9 Segundo Fábio Konder Comparato (2014, p. 54), “em nenhuma civilização no passado, jamais se admitiu o acúmulo de bens materiais como finalidade última da vida. Ainda que no judaísmo, em certas igrejas cristãs, como a calvinista, e no islamismo a riqueza seja considerada uma recompensa divina, nem por isso ela deve ser procurada por si mesma."

10 "No mundo contemporâneo, titular do poder capitalista não é uma pessoa determinada, mas um conjunto de pessoas ou organizações. Nesse conjunto, podem-se distinguir os empresários propriamente ditos, ou seja, aqueles que detêm o comando de empresas, e aqueles que, não possuindo o comando direto de empresa alguma, são, não obstante, detentores de grandes recursos monetários de investimento ou financiamento, ou seja, os capitalistas, no sentido próprio do vocábulo" (COMPARATO, 2014, p. 121). 
muito se questiona sobre a mitigação de direitos sociais em países não desenvolvidos, diversos consumidores demonstram não se importar com a procedência dos bens postos à sua disposição do mercado local, ainda que sejam fruto de labor em condições desumanas.

Por outro lado, com o advento da especialização da mão de obra e o barateamento da produção de bens e da prestação de serviços, cada vez mais as grandes empresas tem migrado suas filiais para outros Estados.

A mobilidade possibilitada pela globalização, embora beneficie as empresas, permitindoas buscar oportunidades resultantes na redução do custo operacional, enseja também graves danos sociais ao deixar uma onda de desempregados, pois conforme versa Bauman (1999), os efeitos dessa mudança guarnecem imóveis. Desta forma, o desemprego, a queda na arrecadação tributária e o aumento das prestações sociais financiadas pelo governo se tornam uma indesejada realidade.

Decorrente de todo o contexto aqui traçado é que as empresas são apontadas como as instituições vitoriosas do final da dicotomia real entre capitalismosocialismo que ocorreu no final do século XX. E isso ocorre em função de tais empresas possuírem poderio econômico, financeiro, técnico e informacional em muito superior ao do Estado-nação, o que permite que migrem partes de seu setor produtivo para países em desenvolvimento em busca de menores tributações, salários e, consequentemente, não propiciem condições para efetivar os Direitos Humanos em tais localidades. Tudo em busca do aumento do lucro de forma indiscriminada, independentemente da existência de um sistema global de proteção dos Direitos Humanos (BENACCHIO; VAILATTI, 2016, p. 17-18).

Cumpre destacar ainda que a adoção de políticas que vulneram a proteção aos Direitos Humanos viabiliza a ocorrência do dumping social, ou seja, passa a haver o desatendimento frequente às garantias laborais mínimas, prejudicando assim, todos aqueles que estão sujeitos às relações laborais. ${ }^{11}$

Destarte, deve-se salientar que embora exponham a sociedade a inúmeros problemas, as empresas transnacionais devem manter sua natureza econômica e buscar a acumulação de riquezas, mas como destaca Amartya Sen (2010, p. 28), "sem desconsiderar a importância do crescimento econômico, precisamos enxergar além dele."

Por isso, não só as empresas, mas também o Estado e a sociedade devem se portar de maneira a respeitar todos os direitos inerentes à pessoa humana, não adotando o acúmulo de riqueza como um fim da atividade econômica.

\section{ASPECTOS ECONÔMICO-CONSTITUCIONAIS DA PROTEÇÃO HUMANA E DO DESENVOLVIMENTO NO BRASIL}

Com o advento da globalização e a integração econômica mundial, muitas barreiras

11 "Como o salário do trabalhador representa relevante obstáculo para o aumento do lucro, explora-se a mão-de-obra para a obtenção de menores custos de produção, o que permite também a diminuição do preço de venda, instigando, assim, a prática de dumping social [...]" (FRAHM; VILLATORE, 2004, p. 286). 
comerciais desapareceram e diversos problemas sociais surgiram. Ao mesmo tempo em que vários povos começaram a interagir, passaram também a concorrer profissionalmente, chegando, em alguns casos, a fechar-se ao mundo moderno na tentativa de preservar suas tradições, as quais também ganharam um viés comercial no mercado moderno ${ }^{12}$.

Nessa linha, Eros Roberto Grau (2015) entende que a sociedade civil passou a ter sua liberdade comprometida pelo aumento da competição econômica global e pelo surgimento de novos tipos de exclusão social baseada em raça, nacionalidade, religião ou qualquer outra característica pessoal.

A exclusão social causada por características de determinado grupo pode acabar sendo perpetrada à medida que certos cargos e remunerações passam a ser ocupados por uma seleta classe dominante, consolidando todas as discrepâncias historicamente estabelecidas pelo modelo capitalista.

Embora a globalização tenha trazido a promessa de que os padrões de vida em todo o mundo seriam elevados, é possível perceber que a grande maioria dos países ainda não atingiu os padrões inicialmente imaginados, e um dos motivos que os impedem é o capital especulativo, o qual migra para o Estado e o deixa ao primeiro sinal de instabilidade política ou financeira (STIGLITZ, 2007).

Isso só contribui para o empobrecimento das populações pertencentes a Estados não desenvolvidos, e subsequentemente, à sua marginalização e discriminação se comparados com populações de países tidos como desenvolvidos.

Com isso, objetivando amenizar os efeitos negativos da globalização, muitos Estados passaram adotar normas e políticas públicas que visam amparar sua população, a fim de protegê-la dos reflexos gerados pela atividade econômica, o que nem sempre tem se mostrado eficaz ${ }^{13}$.

O Brasil, fundado em raízes neoliberais, visando conciliar o desenvolvimento econômico e a proteção de seu povo, dispôs em sua Constituição Federal uma gama de direitos e garantias individuais e coletivos, além de diversos princípios norteadores da atividade econômica, almejando impor limites ao exercício da atividade comercial no país.

Desta maneira, não é errado dizer que tais princípios visam assegurar o pleno desenvolvimento da atividade comercial no Brasil, resguardando a dignidade da pessoa humana no habito das relações econômicas, de modo seja possível propiciar uma existência digna a todos.

Sendo a proteção à dignidade da pessoa humana ${ }^{14}$ um dos fundamentos da República Federativa do Brasil (art. $1^{\circ}$, III, CF), tem-se que o Poder Público nacional deve buscar proteger o ser humano de todo tipo de ofensa e humilhação, garantindo ainda condições mínimas à sua

12 Para Sandel (2018, p. 16), “[...] em consequência, sem que nos déssemos conta, sem mesmo chegar a tomar uma decisão a respeito, fomos resvalando da situação de ter uma economia de mercado para a de ser uma sociedade de mercado."

13 “Agravando o cenário econômico-jurídico, percebe-se, na atual conjuntura, que desde a década de 70 há o crescente esvaziamento da função estatal de executar políticas sociais em função da quebra do compromisso keynesiano, do debilitamento do estado do bem-estar, do aumento do poder econômico das empresas transnacionais nas decisões políticas e da constante influência neo-liberal." (FRAHM; VILLATORE, 2004, p. 290).

14 Entende-se por dignidade da pessoa humana a existência de uma gama de elementos capazes de compor o mínimo necessário à vida e ao bem-estar de cada indivíduo - como moradia, saúde, trabalho -, sendo esta uma característica inata a todos, estando o Direito encarregado de declarar e assegurar tal condição (BRITTO, 2016). 
subsistência (TAVARES, 2011).

A observância dos princípios da República, bem como dos princípios da ordem econômica, deve ser integrada, vez que tais elementos atuam de maneira conjunta a fim de propiciar o pleno desenvolvimento nacional (art. $3^{\circ}$, II da $\mathrm{CF}$ ). Ademais, a interdependência entre princípios e objetivos constitucionais não deve se conter ao âmbito legal, sendo necessário efetivar esta integração com base na moral, na política e na cultura nacional (TAVARES, 2011), para que assim seja possível instituir políticas de gestão mais amplas e eficazes.

Em outras palavras, a proteção à dignidade humana, ao meio ambiente e a redução das desigualdades regionais e sociais não devem ser constituídas como um entrave para o incentivo à livre iniciativa e à livre concorrência, permitindo, uma efetiva valorização do trabalho e a busca do pleno emprego.

Ocorre que o desenvolvimento gerado pelo exercício da atividade econômica não beneficia apenas o Estado, mas também a sociedade, de maneira direta e indireta, pois além de melhor distribuir renda, aumentar os postos laborais e modernizar a tecnologia nacional, possibilita ainda ao Estado ascender sua arrecadação tributária, fortalecendo o mercado interno e possibilitando que empresas nacionais ganhem maior competitividade no cenário econômico internacional.

Nessa linha, entende Amartya Sen (2010, p. 61):

O crescimento econômico pode ajudar não só elevando rendas privadas, mas também possibilitando ao Estado financiar a seguridade social e a intervenção governamental ativa. Portanto, a contribuição do crescimento econômico tem de ser julgado não apenas pelo aumento de rendas privadas, mas também pela expansão dos serviços sociais (incluindo, em muitos casos, redes de segurança social) que o crescimento econômico pode possibilitar.

No entanto, não se pode olvidar que o desenvolvimento está diretamente atrelado ao domínio do conhecimento, o qual é adquirido com base na educação ${ }^{15}$. Com a evolução da humanidade, dominar o saber se tornou um diferencial capaz de ensejar a vitória ou derrota de muitos povos em meio a conflitos armados. Hoje, por outro lado, o conhecimento é constantemente explorado com fins negociais, não apenas no setor armamentista, mas comercial de modo geral.

Atualmente, investir na especialização a mão de obra é algo cada vez mais frequente em muitos Estados, normalmente através de políticas públicas de financiamento educacional, ou por necessidade da iniciativa privada, a qual acaba por custear cursos de capacitação para seus funcionários, a fim de que atendam suas necessidades operacionais. ${ }^{16}$

Ademais, é dever do Estado prover, através de suas políticas, meios para a correta distribuição de renda, pois nada adiantará instruir a pessoa individualmente considerada, sem

15 Para Stiglitz (2007, p. 95), “o que separa os países mais desenvolvidos dos outros não é apenas uma distância em recursos, mas um abismo em conhecimento, motivo pelo qual os investimentos em educação e tecnologia - em larga medida, do governo - são tão importantes."

16 Stiglitz (2007, p. 118) entende que "os países que não investem amplamente em educação encontram dificuldades para atrair investimentos externos em negócios que dependem de uma força de trabalho especializada - e hoje cada vez mais negócios dependem desse tipo de mão-de-obra." 
educar a coletividade. Logo, o acesso à educação deve possibilitar que o povo seja capaz de assumir uma postura crítica na tomada de decisões de âmbito político, sob pena de haver graves violações às condições fundamentais da política participativa (SEN, 2010).

Destaca-se também a importância de impedir a prática de atos anticoncorrênciais, devendo haver um rígido combate à instituição de monopólios, oligopólios e a formação de cartéis, vez que a manipulação do mercado pela iniciativa privada gera incontáveis danos ao mercado interno e à coletividade, restringindo o número de concorrentes, impedindo a inovação e impossibilitando o barateamento dos produtos e serviços.

Ou seja, a adoção de uma postura ativa do Poder Público na regulação do mercado contribui para a manutenção a livre concorrência (art. 170, IV, CF), da proteção ao consumidor (art. 170, V, CF), além de colaborar para a o desenvolvimento das empresas nacionais.

Importante destacar que embora o consumismo tenha se tornado um modo de viver na modernidade, não se pode preterir o desenvolvimento econômico em detrimento do meio ambiente, nem a proteção do meio ambiente ao desenvolvimento econômico.

Mesmo no exercício da atividade econômica os seres humanos devem respeitar os limites regenerativos do planeta, pois todos dependem da biodiversidade existente para que haja o correto equilíbrio ecológico, além de tentar evitar a ocorrência de situações como o aquecimento global e o ingresso de animais silvestre em polos urbanos.

Desta forma, o inciso VI do artigo 170 da Constituição Federal elenca a proteção do meio ambiente como um dos princípios da ordem econômica na tentativa de resguardar esse bem tão importante à vida no planeta. Logo, a defesa do meio ambiente está intrinsecamente ligada ao desenvolvimento nacional, pleno emprego e valorização do trabalho, vez que estes são instrumentos capazes de embasar a existência digna do ser humano (GRAU, 2015).

Cabe destacar ainda que para conquistar a soberania nacional econômica, prevista no inciso I do artigo 170, faz-se necessário fomentar o mercado interno por meio do tratamento favorecido às empresas de pequeno porte constituídas sob as leis brasileiras e que tenham sua sede e administração no País (art. 170, IX, CF), bem como possibilitar o acesso ao pleno emprego (art. 170, VIII, CF) ${ }^{17}$.

Como bem explica Eros Roberto Grau (2015), afirmar a soberania nacional econômica supõe a modernização da economia e não o seu isolamento, de modo a permitir uma ruptura na relação de dependência entre Estados desenvolvidos e em desenvolvimento.

A quebra da dependência econômica entre os Estados possibilita, dentre outras coisas, maior participação de empresas brasileiras no cenário comercial internacional. No entanto, para que está participação seja efetiva, o Estado deve implementar mecanismos que viabilizem o surgimento de novas empresas em território nacional, bem como as resguarde dos abusos ao poder econômico praticados por agentes já consolidados no mercado nacional.

Embora as companhias com maior poder financeiro costumem tomar suas decisões com

17 A partir do que defende Ignacy Sachs (2008), tem-se que tal princípio busca não o pleno emprega em seu sentido estrito, mas assegurar àquelas pessoas que possam e queiram trabalhar, o emprego digno ou o auto-emprego, de modo a conciliar o crescimento econômico com a sustentabilidade social. 
base em estudos e avaliações de custo operacional e expectativas de lucro, o Estado não pode deixar que a instalação e operação dessas empresas viole os direitos inerentes à dignidade de seus cidadãos ou degradem o meio no qual estão alocadas, pois a dignidade humana e a valorização do trabalho devem ser tidos como parâmetro basilar para o exercício de qualquer atividade econômica.

Deste modo, buscando o desenvolvimento nacional e o aperfeiçoamento do mercado interno, percebe-se a necessidade da realização de um trabalho conjunto entre o Estado e aqueles que exercem a atividade econômica no país, almejando instituir uma ordem econômica nacional equilibrada, capaz de assegurar a todos uma existência digna.

\section{CONSIDERAÇÕES FINAIS}

O processo de globalização possibilitou a evolução das relações pelo mundo, integrando Estados, empresas e a sociedade de forma a tornar o exercício da atividade econômica uma questão internacional.

A fim de melhor aproveitar as benesses do modelo capitalista, muitas empresas passaram a ser consideradas transnacionais devido ao seu modelo operacional. Ocorre que devido à influência financeira dessas companhias, diversos países acreditam que a presença de empresas transnacionais em seu território gera um efeito benéfico ao desenvolvimento socioeconômico da região.

Entretanto, as transnacionais, visando ampliar o lucro e reduzir os custos, almejam utilizar mão-de-obra com baixos encargos, fator este que torna muitos Estados propensos a mitigaram direitos historicamente conquistados pelo respectivo povo, gerando assim, certa instabilidade em longo prazo.

Este anseio de lucratividade fez com que o sistema capitalista desenvolvesse suas relações comerciais em velocidade nunca antes vista, superando as morosas legislações protetivas da dignidade humana, tornando-as, em muitos casos, genéricas.

$\mathrm{O}$ acesso à informação ensejou uma inegável mudança nos valores comuns pelo mundo, declarando moralmente inaceitável o exercício de qualquer atividade capaz de ferir garantias sociais.

Embora o mercado seja um ambiente competitivo, o desenvolvimento nacional e o respeito à dignidade humana não podem ser deixadas de lado, pois as relações comerciais têm por fim assegurar uma a existência digna de todos, compreendendo dentre outras coisas, a efetiva distribuição de renda.

Destarte, conclui-se que o exercício da atividade econômica no mundo globalizado é um fator essencial ao desenvolvimento social, a qual deve ser exercida em consonância com as diversas determinações normativas dos diversos Estados, evitando toda e qualquer condição prejudicial aos cidadãos.

Ainda que haja diversas discussões a respeito da proteção e aplicação dos Direitos Humanos nas relações de mercado, entende-se que tais direitos são limitares necessários da atividade exercida pelos diferentes agentes econômicos, visando impedir que o mero acúmulo de 
capital vulnere a condição humana.

Nessa linha, a Constituição Federal brasileira elencou diversos princípios regentes da ordem econômica, os quais visam estabelecer limites para o mercado interno e auxiliar os agentes econômicos nele atuantes a contribuir com a consecução dos objetivos da República, observando seus fundamentos, vez que a promoção do bem estar social não compete apenas ao Estado, mas a todos aqueles que de um modo ou de outro possam ajudar a tornar dignidade humana uma realidade e não apenas uma abstração ideológica.

\section{REFERÊNCIAS}

ARAGÃO, Alexandre Santos de. Empresas estatais: o regime jurídico das empresas públicas e sociedades de economia mista. São Paulo: Forense, 2017.

BAUMAN, Zygmunt. Globalização: consequências humanas. Rio de Janeiro: Zahar, 1999.

BENACCHIO, Marcelo; VAILATTI, Diogo Basilio. Empresas transnacionais, globalização e direitos humanos. In: BENACCHIO, Marcelo (coord.). A sustentabilidade da relação entre empresas transnacionais e direitos humanos. Curitiba: CRV, 2016. p. 13-28.

BRASIL. [Constituição (1988)]. Constituição da República Federativa do Brasil de 1988. Brasília: Presidência da República, 1988. Disponível em: http://www.planalto.gov.br/ccivil_03/ constituicao/constituicaocompilado.htm. Acesso em: 11 mar. 2019.

BRITTO, Carlos Ayres. O humanismo como categoria constitucional. Belo Horizonte: Fórum, 2016.

COMPARATO, Fábio Konder. A civilização capitalista: para compreender o mundo em que vivemos. 2. ed. São Paulo: Saraiva, 2014.

CUNHA, Leandro Reinaldo da; DOMINGOS, Terezinha de Oliveira. A responsabilidade da empresa como garantia do desenvolvimento econômico e social. In: SILVEIRA, Vladmir Oliveira da; MEZZAROBA, Orides (coord.). Empresa, sustentabilidade e funcionalização do direito. São Paulo: Revista dos Tribunais, 2011. v. 2.

FRAHM, Carina; VILLATORE, Marco Antônio César. Dumping social e o Direito do trabalho. In: GOMES, Eduardo Biacchi; REIS, Tarcísio Hardman (org.). Globalização e o comércio internacional no Direito da Integração. São Paulo: Aduaneiras, 2004. p. 285-323.

GRAU, Eros Roberto. A ordem econômica na Constituição de 1988. 17. ed. São Paulo: Malheiros, 2015.

NALINI, José Renato. Ética ambiental. 4. ed. São Paulo: Revista dos Tribunais, 2015.

NALINI, José Renato. Sustentabilidade e ética empresarial. In: SILVEIRA, Vladmir Oliveira da; MEZZAROBA, Orides (coord.). Empresa, sustentabilidade e funcionalização do direito. São Paulo: Revista dos Tribunais, 2011. v. 2, p. 119-143.

NUSDEO, Fabio; MAGLIANO, Raymundo; FERRAZ JUNIOR, Tercio Sampaio. Primeiro 
encontro: poder econômico: o jogo e as regras. In: FERRAZ JUNIOR, Tercio Sampaio; SALOMÃO FILHO, Calixto; NUSDEO, Fabio (org.). Poder econômico: direito, pobreza, violência, corrupção. Barueri: Manole, 2009. p. 1-42.

RIBEIRO, Daniela Menengoti; OLIVEIRA, Jose Sebastiao de. Promoção e tutela dos direitos da personalidade pelas empresas transnacionais. In: BENACCHIO, Marcelo (coord.). A sustentabilidade da relação entre empresas transnacionais e direitos humanos. Curitiba: CRV, 2016. p. 29-52.

RUGGIE, John Gerand. Quando os negócios são apenas negócios: as corporações multinacionais e os Direitos Humanos. São Paulo: Planeta Sustentável, 2014.

SACHS, Ignacy. Desenvolvimento includente, sustentável, sustentado. Rio de Janeiro: Garamond, 2008.

SANDEL, Michael J. O que o dinheiro não compra: os limites morais do mercado. 10. ed. Rio de Janeiro: Civilização Brasileira, 2018.

SEN, Amartya. Desenvolvimento como liberdade. São Paulo: Companhia das Letras, 2010.

SMITH, Adam. A riqueza das nações. 3. ed. Curitiba: Juruá, 2015.

STIGLITZ, Joseph Eugene. Globalização: como dar certo. São Paulo: Companhia das Letras, 2007.

TAVARES, André Ramos. Direito constitucional econômico. 3. ed. São Paulo: Método, 2011.

VASCONCELLlOS, Marco Antonio Sandoval de; GARCIA, Manuel Enriquez. Fundamentos de economia. 3. ed. São Paulo: Saraiva, 2008.

WEBER, Max. A ética protestante e o "espírito" do capitalismo. São Paulo: Companhias das Letras, 2004.

Como citar: OLIVEIRA, Jeferson Sousa; BENACCHIO, Marcelo. Princípios constitucionais da ordem econômica como diretrizes do desenvolvimento socioeconômico brasileiro. Revista do Direito Público, Londrina, v. 15, n. 1, p. 100-113, abr. 2020. DOI: 10.5433/24157-108104-1.2020v1 5n1p. 100. ISSN: 1980-511X

Recebido em: 04/02/2019

Aprovado em: 08/04/2019 